\title{
Green thermoplastic poly(ether-urethane)s - synthesis, chemical structure and selected properties investigation*)
}

\author{
Paulina Kasprzyk ${ }^{1)}$, Kamila Błażek ${ }^{1)}$, Paulina Parcheta ${ }^{1)}$, Janusz Datta ${ }^{1)}$ **) \\ DOI: dx.doi.org/10.14314/polimery.2020.10.2
}

\begin{abstract}
This work aimed to characterize the effect of the monomers chemical structure on the selected properties of the green thermoplastic poly(ether-urethane)s. During synthesis two types of polyether biopolyols, 4,4'-diphenylmethane diisocyanate and bio-based 1,3-propanediol were employed. Materials were synthesized with the use of two step method and two different prepolymers, which were mixed together in equimolar quantities. Obtained materials were characterized by spectroscopic method, size exclusion chromatography, thermal, static mechanical and melt flow index tests. It was confirmed that the prepolymers mixture has an effect on the thermal stability and selected properties of synthesized green thermoplastic poly(ether-urethane)s.
\end{abstract}

Keywords: thermoplastic polyurethanes, green poly(ether-urethane)s, bio-based polyol, chemical structure analysis, thermal analysis, melt flow index.

\section{Zielone termoplastyczne elastomery poli(etero-uretanowe) - synteza i badania struktury chemicznej oraz wybranych właściwości}

\begin{abstract}
Streszczenie: Zbadano wpływ struktury chemicznej monomerów na wybrane właściwości zielonych termoplastycznych elastomerów poli(etero-uretanowych). W syntezie wykorzystano dwa rodzaje biopolioli polieterowych, 4,4'-diizocyjanian difenylometanu oraz 1,3-propanodiol pochodzenia roślinnego. Materiały zsyntezowano z wykorzystaniem dwustopniowej metody, w której zastosowano równomolową mieszaninę dwóch prepolimerów. Otrzymane materiały scharakteryzowano za pomocą metod spektroskopowych, chromatografii żelowej, w statycznej próbie rozciągania, w badaniach termicznych oraz na podstawie wskaźnika szybkości płynięcia. Stwierdzono, że mieszanina prepolimerów wpływa na stabilność termiczną oraz wybrane właściwości otrzymanych zielonych termoplastycznych elastomerów poli(etero-uretanowych).
\end{abstract}

Słowa kluczowe: termoplastyczne poliuretany, zielone poli(etero-uretany), biopoliole, analiza struktury chemicznej, analiza termiczna, wskaźnik szybkości płynięcia.

Cast polyurethanes (PURs) are based on three main components: polyols, isocyanates and chain extenders. Modifying molar ratio of these components and change them based on their chemical structure, it is possible to obtain thermoplastic and/or elastomeric materials, plastomers or polyurethane resins. Taking under consideration two primary types of polyols, polyester and polyether polyols, the first mentioned allow obtaining poly(esterurethane) materials characterized by higher mechanical, thermal and organic solvent resistance compared to polyether polyol-based PURs. Moreover, poly(ester-ure-

\footnotetext{
1) Gdańsk University of Technology, Faculty of Chemistry, Department of Polymers Technology, G. Narutowicza 11/12, 80233 Gdańsk, Poland.

*) Material contained in this article was presented at the Science and Technology Conference on "Polyurethanes 2019", Ustroń, Poland, 13-16 October 2019.

**) Author for correspondence: janusz.datta@pg.edu.pl
}

thane)s are lower resistance on hydrolysis, so they are more liable on biodegradation. Nevertheless, poly(etherurethane)s are generally more elastic [1,2].

Selected properties of PURs are related with segmental construction of macromolecules. Polyols constitute soft segments at the PURs morphology and are in charge of elasticity, elongation, lower values of glass transitions and good mechanical properties at low temperature. Isocyanates (IC) and chain extenders constitute hard segments. The more symmetric IC, the highest PURs capability for crystallization and phase separation. Moreover, symmetric isocyanates make polyurethanes more resistant to abrasion and they are characterized by higher hardness, Young modulus and tensile strength [3].

In our previous work [4], there was investigated the influence of the number of unreacted isocyanate groups and the $[\mathrm{NCO}] /[\mathrm{OH}]$ molar ratio during the chain extension of prepolymer during the polymerization process on the structure, processing and selected properties of 
thermoplastic poly(ether-urethane)s. Materials were synthesized with the use of MDI (4,4'-diphenylmethane diisocyanate) and PO3G [poly(trimethylene glycol)] bio-based polyether polyol, where 6, 7 and $8 \%$ of unreacted isocyanate groups were employed. As a chain extender, bio-based 1,4-butanediol was used. It was confirmed that the concentration of unreacted isocyanate groups in the prepolymer affects the degree of the phase separation of poly(ether-urethane)s. It was demonstrated that bioTPURs (thermoplastic polyurethanes) obtained from the prepolymer containing $8.0 \%$ of unreacted [ $\mathrm{NCO}$ ] groups revealed the highest content of hard segments. Moreover, the results affirmed that the content of hard segments is responsible for the values of tensile strength and Young's modulus. It was also found that the melt flow index (MFI) can be correlated to the chemical structure and dynamic mechanical properties of the polyurethanes. It was demonstrated that the energy activation and MFI are strongly dependent on the number of hydrogen bonds between the hard segments. It was confirmed that the higher concentration of unreacted isocyanate groups led to materials with higher energy activation and lower value of melt flow index due to the higher concentration of hydrogen bonds.

Z. Shen et al. [5] 6-hexamethylene diisocyanate based polyurethanes (HDIPUs) described the comparison between non-isocyanate (NIPU) and HDI (hexamethylene diisocyanate)-based poly(ether urethane)s (HDIPU) prepared with the use of 1,6-hexamethylene glycol (HDO) and poly(oxytetramethylene glycol) (PTMG) as a polyether polyol. The results indicated the primary differences between NIPU and HDIPU at the structural distinction which was originated from the hard segment. The Researchers indicate the higher content of urea in the hard segments for NIPUs than HDIPUs. Due to that, the strength of hydrogen bonding between hard segments and the crystallinity of the hard phase were lower than those of HDIPUs. Higher phase mixing of NIPUs resulted in their lower thermal and mechanical properties.

Kumagai and co-workers [6] study the effect of the segmented structure of the poly(ether-urethane) elastomers (EPUs) on the materials pyrolysis characteristics. EPU was synthesized based on MDI, BDO (1,4-butanediol), and PTMG. It was measured that the segmented structure of the EPU has an impact on the decomposition mechanism. Authors demonstrate that the reaction selectivity depends on the different conformations of the urethane bonds, formed by $\mathrm{H}$-bonds between either two urethane units $(\mathrm{N}-\mathrm{H}$ and $\mathrm{C}=\mathrm{O})$ or urethane units and ether oxygens in the soft segments (N-H and -O-). Moreover, it was determined that only the selectivity for urethane bond cleavage is strongly influenced by the content of hard and soft segments, while other reaction mechanisms during pyrolysis are not influenced.

M. Saenz-Perez et al. [7] described a comparison between poly(ether-urethane)s based on MDI and HDI, their thermal stability, shape-memory behavior and mechanical properties. The hard segments of the materials were composed of diisocyanate [toluene 2,4-diisocyanate (TDI) or 4,4'-methylene diphenyl diisocyanate (MDI)] and a chain extender,1,4- butanediol (BDO), when the soft segments were prepared by a polyol, poly(oxytetramethylene) glycol (PTMG). With increasing hard-to-soft segment content between 30 and $70 \mathrm{wt} \%$, the glass transition temperature of the prepared polyurethanes increased from 52.1 to $8.6^{\circ} \mathrm{C}$. Furthermore, it was confirmed that the shape memory effect depends on hydrogen bonded molecular interactions and TDI-based shape memory polyurethanes are more appropriate for their commercial use.

This work aimed to investigate the impact of the usage of two different prepolymers based on bio-based polyether polyols characterized by different average molecular weight, on the segmented structure of the resulted green thermoplastic poly(ether-urethane)s. Hard segments were composed with the use of 4,4'-diphenylmethane diisocyanate, MDI, and 1,3-propanediol, PDO. Thermal stability, thermo-mechanical and mechanical properties were also measured.

\section{EXPERIMENTAL PART}

\section{Materials}

For the synthesis of green thermoplastic poly(etherurethane)s, the fully bio-based polyether polyols like poly(trimethylene glycol) (PO3G, $M n=1000 \mathrm{~g} / \mathrm{mol}$ or $2700 \mathrm{~g} / \mathrm{mol}$ ) were employed. Polyether polyols were kindly supplied by Allessa, Germany. All polyurethane materials were synthesized with the use of aromatic diisocyanate, 4,4'-diphenylmethane diisocyanate (MDI provided by BorsodChem, Hungary).

1,3-propanediol (PDO, Susterra, kindly supplied by DuPont, USA), low molecular weight bio-based glycol, was used as the chain extender.

DABCO, which was used as a catalyst was purchased from Sigma-Aldrich (Poland).

All other compounds were used in the analytical grade for the analytical measurement methods.

\section{Green thermoplastic poly(ether-urethane) preparation}

Thermoplastic poly(ether-urethane)s obtained with the use of PO3G bio-based polyols, MDI and PDO as a chain extender, were synthesized by a two-step method. Bio-based polyols were degassed under vacuum for $2 \mathrm{~h}$ at $95^{\circ} \mathrm{C}$ to remove the moisture contained therein. The urethane prepolymers were synthesized with the use of dried PO3Gs, MDI and phosphoric acid as a stabilizer for $3 \mathrm{~h}$ at $85^{\circ} \mathrm{C}$. The excess of isocyanate groups equaled $6 \%$, which was determined in accordance with ISO 14896 : 2010 standard. In the next step, the urethane prepolymers were extended with bio-based PDO, using $0.3 \%$ DABCO as a catalyst. Green thermoplastic poly(ether-urethane)s synthesized with the mixture of two prepolymers (based on 
two different polyols) were synthesized on a 50/50 weight percent ratio of prepolymers mixture. The used molar ratio of $[\mathrm{NCO}] /[\mathrm{OH}]$ groups equaled $0.9,0.95$ and 1.0 for each formulation. Finally, the structure of the green thermoplastic poly(ether-urethane)s was established during curing in a laboratory dryer at $100^{\circ} \mathrm{C}$ for $24 \mathrm{~h}$.

\section{Methods of testing}

- Fourier Transform Infrared Spectroscopy (FT-IR) was used to obtain the spectra of the synthesized bio-based thermoplastic poly(ether-urethane)s to indicate the characteristic functional groups for these materials. The measurements were carried out using a Nicolet 8700 FTIR spectrometer (Thermo Electron Corporation, USA) with the use of the ATR technique, 64 scans in the wave number range from 4500 to $500 \mathrm{~cm}^{-1}$ and the resolution $4 \mathrm{~cm}^{-1}$. All samples were measured under room temperature. The obtained results allowed to determine the degree of phase separation (DPS) and the degree of phase mixing (DPM). Calculation method based on the amounts of free carbonyl bonded and H-bonded in amorphous and ordered regions. After the deconvolution of spectrum in the carbonyl region, the following equations $[8,9]$ were used:

$$
\begin{gathered}
D P S=R /(R+1) \\
D P M=1-D P S \\
R=A b / A f
\end{gathered}
$$

where: $R$ - the carbonyl hydrogen bonding index, $A b-$ the absorption intensity of hydrogen-bonded carbonyl, and $A f$ stands for the absorption intensity of free carbonyl, DPS - degree of phase separation, DPM - degree of phase mixing.

- Size Exclusion Chromatography (SEC) was performed to determine the number $(M n)$ and weight average $(M w)$ molecular weights, as well as the dispersity $(\bigoplus)$.

A chromatographic system equipped with a refractive index detector (Shodex, Japan), UV-Vis detector $(\lambda=254 \mathrm{~nm}, \mathrm{LCD} 2084$, Ecom, Czech Republic) and a set of three columns (PLgel with a particle size of $10 \mu \mathrm{m}$, pore size: 50/10E3/10E4 $\AA, 300 \times 7.5\left(\mathrm{~mm}^{2}\right)$, Polymer laboratories, UK) was used. Tetrahydrofuran was applied as the eluent at a $1 \mathrm{~cm}^{3} / \mathrm{min}$ flow rate, and the calibration was done on polystyrene standards.

- Thermogravimetric Analysis (TGA) of prepared bio-based thermoplastic poly(ether-urethane)s was performed using NETZSCH TG 209F1 Libra analyzer. The samples, with a mass around $10 \mathrm{mg}$, were heated from 25 to $700^{\circ} \mathrm{C}$ at a rate of $10^{\circ} \mathrm{C} / \mathrm{min}$, under the nitrogen atmosphere.

- Dynamic Mechanical Thermal Analysis (DMTA) was carried out using the DMA Q800 analyzer (TA Instruments) following ASTM D4065:2012. The rectan- gular samples with dimensions $10 \times 40 \times 2\left(\mathrm{~mm}^{3}\right)$ were prepared for the study. The temperature of the measurement was in the range from -100 to $150^{\circ} \mathrm{C}$, while the heating rate was set at $4^{\circ} \mathrm{C} / \mathrm{min}$, and the frequency at $10 \mathrm{~Hz}$. The results provided information about storage modulus $\left(E^{\prime}\right)$, loss modulus $\left(E^{\prime \prime}\right)$ and tan delta $(\tan \delta)$ as a function of temperature. The glass transition temperature of the soft segments $\left(T_{g S S}\right)$ was determined based on the maximum tan $\delta$ peak.

- The tensile properties, such as tensile strength $\left(T S_{b}\right)$, elongation at break $\left(E_{b}\right)$, and permanent set after the break, were determined with the use of a Zwick/Roell Z020 universal testing machine. The tests were performed following ISO 527, with the crosshead speed set to $100 \mathrm{~mm} / \mathrm{min}$ and the $20 \mathrm{kN}$ load cell. The dumbbell-shaped specimens of all materials were tested. The obtained results are reported as average values calculated from three samples.

- The hardness $(H)$ measurements were performed with a Shore type D Durometer (Zwick/Roell). The specimens were tested under the standard ISO 868. The presented results are the mean values of hardness based on ten independent measurements.

- The melt flow index (MFI) of TPURs samples was examined by Zwick/Roell plastometer, according to ISO 1133:2011. The measurement was performed at $175^{\circ} \mathrm{C}$ applying $5 \mathrm{~kg}$ load.

\section{RESULTS AND DISCUSSION}

\section{Chemical structure analysis}

The presence of characteristic groups in the chemical structure of obtained thermoplastic poly(ether-urethane)s was determined through FT-IR spectroscopy. The spectra presented in Fig. 1 refer to materials with $[\mathrm{NCO}] /[\mathrm{OH}]$ molar ratio equal 0.95 during the prepolymer chain

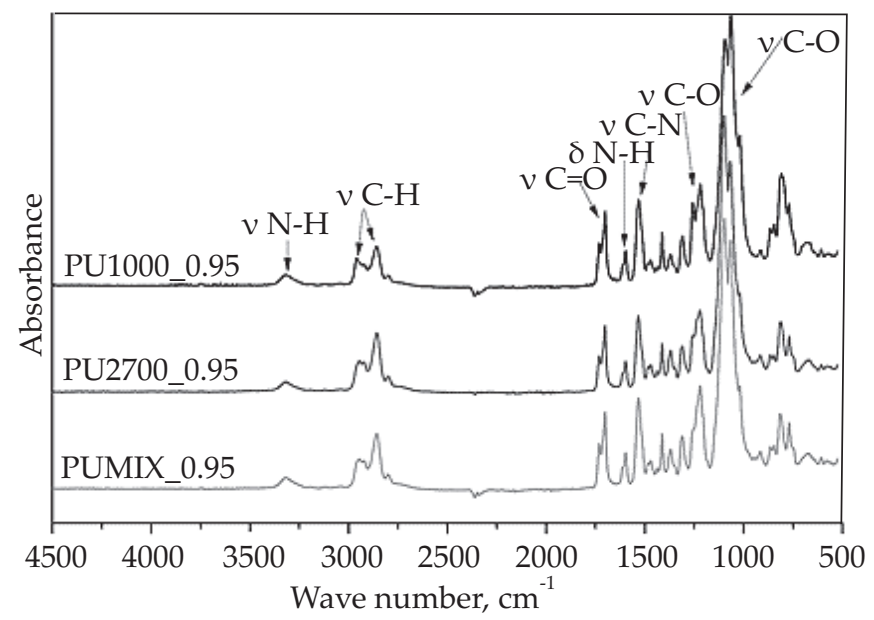

Fig. 1. FT-IR spectra of poly(ether-polyurethane)s synthesized using the polyol with an average molecular weight of $1000 \mathrm{~g} / \mathrm{mol}$, $2700 \mathrm{~g} / \mathrm{mol}$, and the mixture of prepolymers with $[\mathrm{NCO} /[\mathrm{OH}]$ molar ratio during the prepolymer chain extension step equal 0.95 
extension step obtained employing a polyol with an average molecular weight of $1000 \mathrm{~g} / \mathrm{mol}$ and $2700 \mathrm{~g} / \mathrm{mol}$ as well as the mixture of prepolymers.

The absorption band in the range from 2250 to $2270 \mathrm{~cm}^{-1}$ corresponding to the vibrations of free isocyanate (NCO) groups was not detected. This finding indicates that the components (isocyanate and hydroxyl groups) completely reacted under applied conditions [10]. The asymmetric and symmetric stretching vibrations of the $\mathrm{CH}_{2}$ groups occurred at 2958 and $2890 \mathrm{~cm}^{-1}$, respectively. The bands assigned to the characteristic vibrations of urethane bonds are stretching vibrations of N-H groups registered at $3300 \mathrm{~cm}^{-1}$ and the peak corresponding to vibrations of carbonyl groups $(\mathrm{C}=\mathrm{O})$ presented at $1700 \mathrm{~cm}^{-1}$. The FT-IR analysis of polyurethanes should be focused on the carbonyl stretching vibration in the amide I region, which occurs in the range from 1670 to $1750 \mathrm{~cm}^{-1}$. The three stretching absorption bands are usually observed. The peak at $c a .1734 \mathrm{~cm}^{-1}$ is attributable to the non-hydrogen-bonded free carbonyl groups, peak at ca. $1715 \mathrm{~cm}^{-1}$ assigns to the hydrogen-bonded group in the disordered amorphous phase, while that at $c a .1700 \mathrm{~cm}^{-1}$ corresponds to the hydrogen-bonded group in the crystalline phase of hard domains [11]. Concerning obtained materials, the hydrogen-bonded $\mathrm{C}=\mathrm{O}$ group stretching vibration band associated with the amorphous phase is not observed, as shown in Fig. 2.

The out-of-plane bending of $\mathrm{N}-\mathrm{H}$ groups was found at $1598 \mathrm{~cm}^{-1}$. The characteristic stretching vibration of C-N groups in the urethane linkage was detected at $1533 \mathrm{~cm}^{-1}$. Bending vibrations of the methyl and methylene groups derived from the polyol chains, deformation vibration of $-\mathrm{CH}_{3}$ groups and bonds between the carbon atoms were found at the wave numbers in the range from 1360 to $1470 \mathrm{~cm}^{-1}$. The region between 1200 to $950 \mathrm{~cm}^{-1}$ is connected with different interactions of C-O-C groups [12]. The peak at around $1215 \mathrm{~cm}^{-1}$ is attributable to $\mathrm{C}-\mathrm{O}-\mathrm{C}$

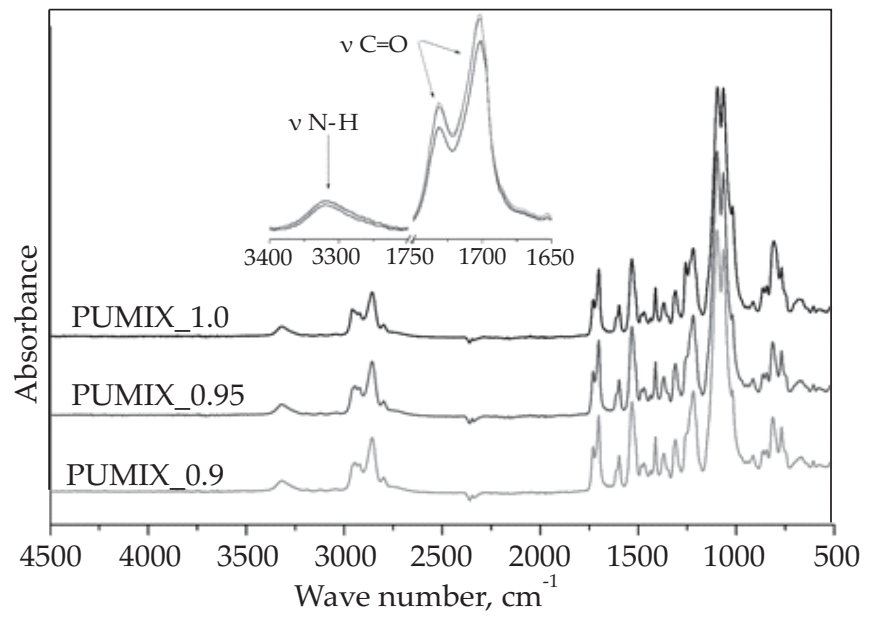

Fig. 2. FT-IR spectra of polyurethanes obtained using a mixture of prepolymers with different $[\mathrm{NCO}] /[\mathrm{OH}]$ molar ratio during the prepolymer chain extension step; the spectrum distinguishes the region characteristic for the absorbance of $\mathrm{N}-\mathrm{H}$ and $\mathrm{C}=\mathrm{O}$ groups
T a b l e 1. The carbonyl hydrogen bonding index $(R)$, the degree of phase separation (DPS) and the degree of phase mixing (DPM) calculated for obtained poly(ether-urethane)s

\begin{tabular}{c|c|c|c}
\hline Code of sample & $R$ & $D P S$ & $D P M$ \\
\hline PU1000_0.95 & 1.8031 & 0.6433 & 0.3567 \\
PU2700_0.95 & 1.8786 & 0.6526 & 0.3474 \\
PUMIX_0.9 & 1.8836 & 0.6532 & 0.3468 \\
PUMIX_0.95 & 1.7756 & 0.6387 & 0.3603 \\
PUMIX_1.0 & 1.7487 & 0.6362 & 0.3638 \\
\hline
\end{tabular}

asymmetric stretching vibration. The characteristic stretching vibration of the free $\mathrm{C}-\mathrm{O}-\mathrm{C}$ bond in the aliphatic polyether polyol chain occurred at $1100 \mathrm{~cm}^{-1}$. In the case of poly(ether-urethane)s, in this region, two characteristic peaks are detected. The absorption band at lower wave numbers ( $\left.c a .1065 \mathrm{~cm}^{-1}\right)$ is assigned to the hydrogen bonding interaction between C-O-C and N-H groups [12]. The chemical structure of all obtained materials is similar, and the small shifts at the wave numbers are caused by the content of hard segments [9].

The degree of phase separation was calculated according to FT-IR analysis to determine the correlation between the chemical structure and the properties of the obtained materials. The deconvolution of the carbonyl peaks in the range from 1600 to $1800 \mathrm{~cm}^{-1}$ was performed using the Origin software. The results are presented in Table 1.

Furthermore, the carbonyl hydrogen bonding index and the degree of phase mixing was also considered. In Fig. 2, the N-H and $\mathrm{C}=\mathrm{O}$ regions of the normalized FT-IR spectra are demonstrated. For all obtained samples, slight differences in the position of the absorption bands can be observed, which confirms slight differences in the chemical structure of the materials. With the increasing content of hard segments, the intensity of the absorption band corresponding to vibrations of carbonyl groups $(\mathrm{C}=\mathrm{O})$ in the crystalline region also increases. The formation of larger HS domains resulted in improved segment separation. Therefore, the intensity of peak is increased as the $[\mathrm{NCO}] /[\mathrm{OH}]$ molar ratio during the prepolymer chain extension step is decreased. This relationship is also observed in the case of the peak attributed to $\mathrm{NH}$ stretching vibrations. Moreover, the intensity of the absorption bands at $1700 \mathrm{~cm}^{-1}$ and $1734 \mathrm{~cm}^{-1}$ is higher for the polyurethanes obtained from the mixture of prepolymers in comparison to materials synthesized using polyols with different average molecular weights (PO3G1000 and PO3G2700).

In the case of all obtained samples, the degree of phase separation (DPS) is above $60 \%$ which means that urethane hard segments are satisfactory separated. Only approximately $35 \%$ of the hard segments are well dispersed within the polyol matrix (see DPM value presented in the Table 1). Slightly higher values of the DPS coefficient were observed for samples obtained from polyol with a higher average molecular weight and mixture of prepolymers than for polyurethane synthesized using PO3G1000. To 
$\mathrm{T}$ a b 1 e 2. The results of SEC measurements

\begin{tabular}{c|c|c|c}
\hline Code of sample & $M_{n}$ & $M_{w}$ & $Ð$ \\
\hline PU1000_0.95 & 36300 & 65400 & 1.80 \\
PU2700_0.95 & 30800 & 54824 & 1.78 \\
PUMIX_0.9 & 20952 & 44210 & 2.11 \\
PUMIX_0.95 & 30000 & 61200 & 2.04 \\
PUMIX_1.0 & 42038 & 86600 & 2.06 \\
\hline
\end{tabular}

sum up, the DPS values are strongly dependent on the length of the used polyols [4, 9]. Good microphase separation is related to high long-range connectivity of hard segments, hence the formation of interconnected hard phase is more presumable [13]. The hydrogen bonds of carbonyl groups occur between the hard segments of the polymer chains. The higher number of hydrogen bonds, the better the phase separation could be obtained. Thus, the $[\mathrm{NCO}] /[\mathrm{OH}]$ molar ratio and consequently content of hard segments have a strong influence on the number of free carbonyl groups and hydrogen-bonded carbonyl groups in ordered crystalline regions [4]. The tendency to creating hydrogen bonds in the carbonyl region is characteristic of polyurethanes with a higher content of hard segments. In parallel, the fraction of hydrogen-bonded carbonyl groups is decreased as the $[\mathrm{NCO}] /[\mathrm{OH}]$ molar ratio is increased. The value of the $R$ index is highest for PU2700_0.95 (when compare samples obtained from different types of polyols) and PUMIX_0.9 (when compare samples with different $[\mathrm{NCO}] /[\mathrm{OH}]$ molar ratio), hence the highest degree of separation between the disparate segments is characteristic for these samples. In conclusion, the chemical structure and above-mentioned indexes strongly depend on the content of hard segments, and consequently $[\mathrm{NCO}] /[\mathrm{OH}]$ molar ratio as well as the length of used polyol.

Molecular weight distribution depended on the type of components, the molar ratio of the components, the used catalyst, but also on the reaction condition. The size exclusion chromatography was used to characterize the number and weight average molecular weight and dis- persity of the synthesized green thermoplastic poly(ether-urethane)s. Table 2 presents the statement of the SEC results.

Measurements showed that the bio-based polyether polyol PO3G with ca. $1000 \mathrm{~g} / \mathrm{mol}$ molecular weight led to bio-TPURs characterized by higher $M n$ and $M w$ than bio-TPURs based on second biopolyol and also a mixture of polyols, in the case of materials prepared based on the same $\mathrm{NCO} / \mathrm{OH}$ ratio. Characteristic is also the fact that increasing $\mathrm{NCO} / \mathrm{OH}$ ratio used during synthesis also led to bio-TPURs featured by higher $M n$ and $M w$. Moreover, usage of two prepolymer mixture allowed to obtain bio-TPURs characterized higher dispersity than bio-TPURs based on one from the bio-based polyether polyols.

\section{Thermal stability analysis}

Thermal properties of thermoplastic polyurethane materials, like thermal stability or phase transition temperatures, strongly depend on applied components and give much important information about materials that determine their future application.

The thermal stability of the obtained bio-TPURs was analyzed with the use of thermogravimetric measurements. Based on the results, TG and DTG curves versus temperature were plotted and presented in Figs. 3 and 4, respectively.

Because of creating many gaseous products during decomposition, thermal degradation of polyurethanes is a complex process $[8,14]$. Due to the segmented structure of the bio-TPURs degradation process is connected with hard and soft segments. Separated peaks on the DTG curve provides information about phase separation of obtained bio-based TPUR materials. TPURs decomposed usually in two steps confirm the segmented structure of obtained materials (Fig. 4). The hard segments built from isocyanates and chain extenders decomposed at the first step, while the soft segments consist of polyols decomposed during the second step. DTG curves showed in

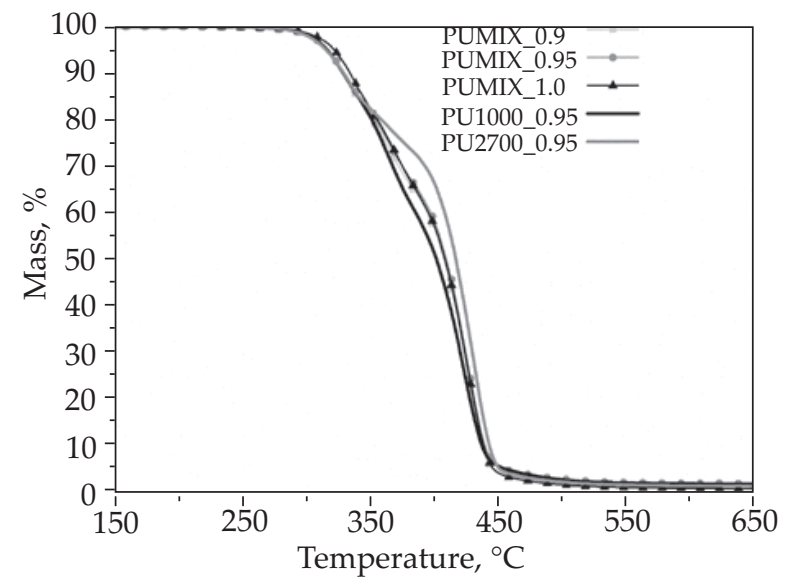

Fig. 3. TG results of the prepared green thermoplastic poly(ether-urethane)s

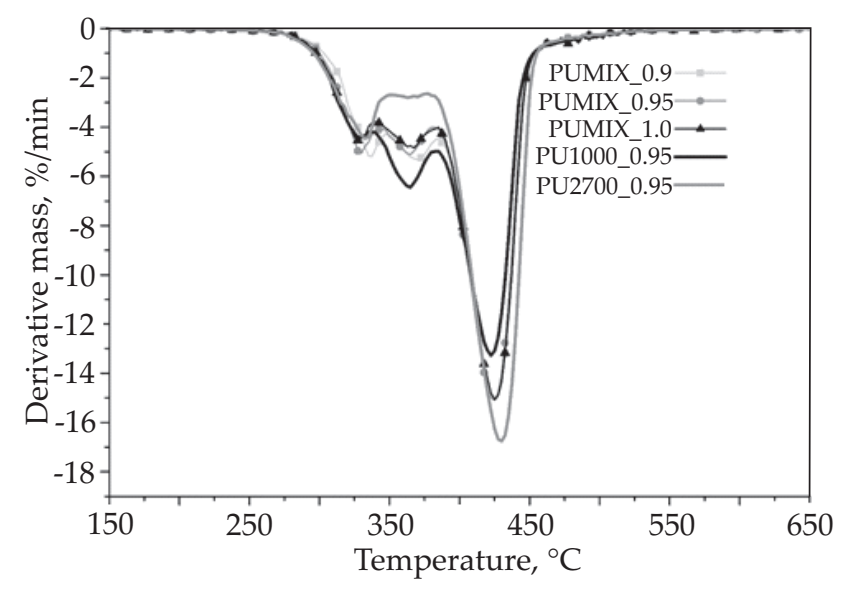

Fig. 4. DTG results of the prepared bio-TPURs 
$\mathrm{T}$ a b 1 e 3. Thermal degradation characteristics of the obtained materials

\begin{tabular}{|c|c|c|c|c|c|c|c|c|c|}
\hline \multirow[b]{2}{*}{ Code of sample } & \multirow{2}{*}{$\begin{array}{l}T_{5 \%} \\
{ }^{\circ} \mathrm{C}\end{array}$} & \multirow{2}{*}{${ }_{{ }^{\circ} \mathrm{C} \%}$} & \multirow{2}{*}{$\begin{array}{l}T_{50 \%} \\
{ }^{\circ} \mathrm{C}\end{array}$} & \multirow{2}{*}{$\begin{array}{l}T_{90 \%} \\
{ }^{\circ} \mathrm{C}\end{array}$} & \multirow{2}{*}{$\begin{array}{l}\text { Char yield at } \\
650^{\circ} \mathrm{C} \text {, wt } \%\end{array}$} & \multicolumn{2}{|c|}{ I step } & \multicolumn{2}{|c|}{ II step } \\
\hline & & & & & & $\begin{array}{c}T_{\max } \\
{ }^{\circ} \mathrm{C}\end{array}$ & $\begin{array}{c}\text { DTG } \\
\% / \min \end{array}$ & $\begin{array}{l}T_{\max } \\
{ }^{\circ} \mathrm{C}\end{array}$ & $\begin{array}{c}\text { DTG } \\
\% / \mathrm{min}\end{array}$ \\
\hline PU1000_0.95 & 316.4 & 326.6 & 400.8 & 436.9 & 2.27 & 328.0 & -4.43 & 422.6 & -13.29 \\
\hline PU2700_0.95 & 312.3 & 327.1 & 416.0 & 442.5 & 1.83 & 333.6 & -4.48 & 429.3 & -16.77 \\
\hline PUMIX_0.9 & 314.0 & 325.1 & 406.4 & 438.1 & 1.26 & 336.5 & -5.24 & 425.1 & -14.98 \\
\hline PUMIX_0.95 & 314.3 & 327.2 & 408.5 & 439.3 & 2.29 & 329.4 & -5.08 & 425.3 & -15.08 \\
\hline PUMIX_1.0 & 319.1 & 332.3 & 408.7 & 440.3 & 1.25 & 327.9 & -4.54 & 425.5 & -15.10 \\
\hline
\end{tabular}

Fig. 4 verified the partially separated peaks of decomposition steps of the obtained bio-TPURs. The results confirmed phase mixing what was also confirmed by FT-IR analysis and calculated DPM and DPS values (Table 1). It is a result of the strong interaction between urethane groups present in the structure of the obtained bioTPURs. This interaction leads to the creation of hydrogen bonding between urethane groups.

Table 3 shows the statement of the most characteristic thermal stability temperatures. Bio-TPUR coded PU1000_0.95 obtained with using PO3G polyether polyol with an average molecular mass of about $1000 \mathrm{~g} / \mathrm{mol}$, characterized the highest value of the $T_{5 \%}$ at $316^{\circ} \mathrm{C}$. It is the temperature of the thermal degradation beginning. Besides sample PUMIX_1.0 which indicates $T_{5 \%}$ at $\mathrm{ca} .319^{\circ} \mathrm{C}$, other materials revealed lower values of the $T_{5 \%}$ temperature. In the case of $T_{50 \%}$ and $T_{90 \%}$, the highest temperature values achieved sample coded PU2700_0.95, synthesized with the use of PO3G polyol with average $\mathrm{Mn}$ about $2700 \mathrm{~g} / \mathrm{mol}$ and the ratio of $\mathrm{NCO} / \mathrm{OH}$ groups at 0.95 . Materials based on prepolymers mixture revealed $T_{10 \%}$, $T_{50 \%}$ and $T_{90 \%}$ values between temperatures characterized samples PU1000_0.95 and PU2700_0.95. Moreover, the results of thermogravimetric analysis allowed to identify that with the increasing ratio of $\mathrm{NCO} / \mathrm{OH}$ groups, temperatures of $T_{5 \%}, T_{10 \%}, T_{50 \%}$ and $T_{90 \%}$ for bio-TPURs based on prepolymers mixture increase. Interesting is the fact that the usage of the prepolymer mixing during bio-TPURs synthesis allowed obtaining materials characterized by higher values of the rate of mass loss for the first step than materials prepared with use one from PO3G polyols. It is mean that hard segments at PUMIX samples degraded faster but at higher temperatures than samples PU1000 and PU2700.

\section{Thermo-mechanical properties}

Dynamic mechanical thermal analysis was carried out for verifying the influence of usage of the prepolymer mixture during bio-TPURs preparation on the obtained materials thermo-mechanical properties. This measurement allowed to determine the glass transition temperature of the soft segments of prepared bio-TPURs, which was assumed as the transition in the $\tan \delta$ curve. The storage modulus is provided to information regarding the material stiffness and the stored energy. Loss modu- lus $E^{\prime \prime}$ is used to measure the energy dissipated as heat, while loss factor ( $\tan \delta$ ) measures the degree of molecular motion $[15,16]$.

The dependence of the $\log E^{\prime}$ versus temperature (Fig. 5) for selected green thermoplastic poly(ether-urethane)s revealed a glassy state and registered the highest storage modulus below the temperature about $-50^{\circ} \mathrm{C}$. After achieving the temperature of $c a .-50^{\circ} \mathrm{C}$, a sharp decreasing trend was observed. It is related to the relaxation of the long chain sequences from bio-based polyether polyols used for the bio-TPURs preparation [8]. The midpoint of the decreasing curve indicates the position of the alpha transition of the soft segments domains. Characteristic is the fact that sample PU2700 revealed a peak at the range from $c a$. -25 to $c a .25^{\circ} \mathrm{C}$. This peak is elated with the melting temperature of the soft segments and occurs in the samples prepared with the use of long chain bio-based polyether polyols $[9,17]$. Glass transition of hard segments is assigned at the width range of temperature above $c a .25^{\circ} \mathrm{C}$. Nevertheless, due to the width range of temperature, there is not possible to determine the $T_{g}$ of HS (hard segment). At the highest temperatures, above $125^{\circ} \mathrm{C}$, the thermoplastic behavior is visible, which is correlated with the melting of hard segments (Fig. 5). The highest $E^{\prime}$ revealed sample PU2700 which indicates the highest stiffness at the range of temperature from -100 to $-25^{\circ} \mathrm{C}$. After achieving $25^{\circ} \mathrm{C}$ this sample characterized the lowest value of storage modulus. Based on the results of

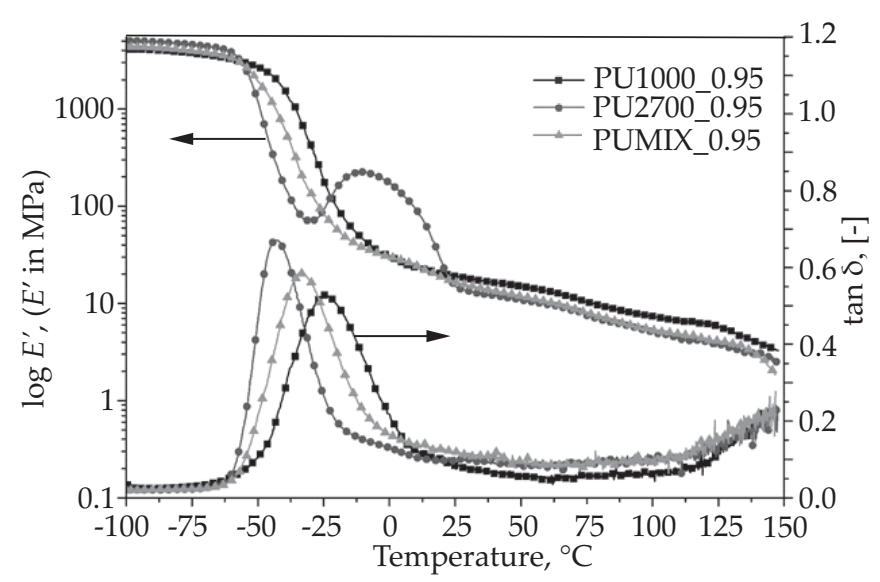

Fig. 5. DMA results presented for the obtained bio-TPURs as $\log$ storage modulus $\left(\log E^{\prime}\right)$ and loss factor $(\tan \delta)$ versus temperature 
T a b l e 4. The statement of the DMA results: the glass transition temperature of the soft segments and values of the tan $\delta$, maximum storage modulus, the temperature of the maximum loss modulus and the value of the maximum loss modulus

\begin{tabular}{c|c|c|c|c|c}
\hline Code of sample & $\begin{array}{c}T_{g S S^{\prime}}{ }^{\circ} \mathrm{C} \\
\text { (DMTA) }\end{array}$ & $\tan \delta$ & $\begin{array}{c}E^{\prime}{ }_{\max } \\
\mathrm{MPa}\end{array}$ & $T_{\max }$ of $E^{\prime \prime}$ & $\begin{array}{c}E^{\prime \prime} \\
\mathrm{MPax}\end{array}$ \\
\hline PU1000_0.95 & -24.6 & 0.514 & 3941 & -39.2 & 415 \\
PU2700_0.95 & -43.0 & 0.671 & 4948 & -52.4 & 615 \\
PUMIX_0.9 & -35.2 & 0.564 & 4502 & -47.2 & 452 \\
PUMIX_0.95 & -33.4 & 0.586 & 4403 & -46.6 & 437 \\
PUMIX_1.0 & -32.1 & 0.602 & 4398 & -45.1 & 387 \\
\hline
\end{tabular}

$T_{g S S}$ - glass transition temperature of the soft segment, $E_{\max }^{\prime}-$ maximum value of storage modulus, $E^{\prime}-$ storage modulus, $E^{\prime \prime}-$ loss modulus.

the dynamic mechanical analysis (Table 4) of the samples, it can be described that the highest ability to the damping capacity characterized samples based PO3G with average molecular weight at $\mathrm{ca} .2700 \mathrm{~g} / \mathrm{mol}$. Considering the applied type of bio-based polyether polyol it can be a statement that bio-TPUR prepared with PO3G 2700 has the lowest $T_{g S S}$ determined based on tan $\delta$ curves. It was affirmed that the tan $\delta$ peak shifts to a higher temperature as SS content increases [18].

\section{Mechanical properties}

The results from the static mechanical testing such as tensile strength $\left(T S_{b}\right)$, elongation at break $\left(E_{b}\right)$ and hardness $(H)$ for all synthesized poly(ether-urethane)s are demonstrated in Table 5.

As the $[\mathrm{NCO}] /[\mathrm{OH}]$ molar ratio during the prepolymer chain extension step increases, both tensile strength and elongation at break increase. With increasing $[\mathrm{NCO}] /[\mathrm{OH}]$ molar ratio, the content of hard segments (HSs) decreases. The high concentration of the HSs influences a more developed reinforcing hard domain structure. At high content of hard segments, the ability of amorphous soft segments chains to align themselves along the stretching direction is limited and they are not able to orient and crystallize under strain [19]. For sample PU2700_0.9, the tensile strength reached $2.7 \mathrm{MPa}$, whereas for the polyurethane PU2700_1.0 it increased more than six times (16.5 MPa). The values of the tensile strength of the samples with the $[\mathrm{NCO}] /[\mathrm{OH}]$ molar ratio of 1.0 are $18.6 \pm 6.4,16.5 \pm 1.7$ and

T a b l e 5. Comparison of the tensile strength $\left(T S_{b}\right)$, elongation at break $\left(E_{b}\right)$ and hardness $(H)$ of prepared poly(ether-urethane)s

\begin{tabular}{c|c|c|c}
\hline Code of sample & $\mathrm{TS}_{b^{\prime}} \mathrm{MPa}$ & $E_{b^{\prime}} \%$ & $H,{ }^{\circ} \mathrm{ShD}$ \\
\hline PU1000_0.9 & $5.5 \pm 0.6$ & $181 \pm 49$ & $20.4 \pm 1.0$ \\
PU1000_0.95 & $10.9 \pm 0.6$ & $485 \pm 76$ & $23.3 \pm 0.6$ \\
PU1000_1.0 & $18.6 \pm 6.4$ & $552 \pm 9$ & $30.7 \pm 0.4$ \\
PU2700_0.9 & $2.7 \pm 0.5$ & $71 \pm 23$ & $15.7 \pm 0.4$ \\
PU2700_0.95 & $7.6 \pm 2.0$ & $361 \pm 66$ & $17.7 \pm 0.7$ \\
PU2700_1.0 & $16.5 \pm 1.7$ & $888 \pm 99$ & $19.3 \pm 0.5$ \\
PUMIX_0.9 & $5.3 \pm 1.2$ & $228 \pm 97$ & $17.3 \pm 0.7$ \\
PUMIX_0.95 & $6.6 \pm 0.7$ & $338 \pm 35$ & $19.2 \pm 0.6$ \\
PUMIX_1.0 & $16.0 \pm 4.5$ & $628 \pm 61$ & $22.3 \pm 0.7$ \\
\hline
\end{tabular}

16.0 \4.5 MPa for PU1000_1.0, PU2700_1.0, and PUMIX_1.0, respectively. These samples displayed the elongation at break above $500 \%$. Regardless of the $[\mathrm{NCO}] /[\mathrm{OH}]$ molar ratio, poly(ether-urethane)s obtained from polyol with an average molecular weight of $1000 \mathrm{~g} / \mathrm{mol}$ have the highest tensile strength of any material yet measured. The values of this parameter ranged from 5.5 to $18.6 \mathrm{MPa}$ for PU1000_0.9 and PU1000_1.0, respectively. It should also be pointed out that materials synthesized from a mixture of prepolymers with different molecular weights achieve the highest tensile strength $(16 \mathrm{MPa})$ and elongation at break $(628 \%)$ when the $[\mathrm{NCO}] /[\mathrm{OH}]$ molar ratio is equal 1.0. However, these values are lower than for poly(etherurethane)s obtained from polyether polyols with a molecular weight of $1000 \mathrm{~g} / \mathrm{mol}$ and $2700 \mathrm{~g} / \mathrm{mol}$, for respective $[\mathrm{NCO}] /[\mathrm{OH}]$ molar ratio, in almost all cases (except for sample coded PUMIX_0.9). This is because better segments (HSs and SSs) mixing has been achieved [9]. Hardness increased constantly with increasing $[\mathrm{NCO}] /[\mathrm{OH}]$ value and as a result of increasing the crystallinity of soft segments. The values varied from 15.7 to $30.7^{\circ} \mathrm{ShD}$. The highest hardness was obtained for materials based on a polyol with a molecular weight of $1000 \mathrm{~g} / \mathrm{mol}$, due to the shorter chains and higher content of hard segments. In contrast to the samples obtained from PO3G2700 polyol, for which the hardness was the lowest in all cases. The hardness of poly(ether-urethane)s obtained from the prepolymer mixture increased with increasing $[\mathrm{NCO}] /[\mathrm{OH}]$ molar ratio during the prepolymer chain extending step and reached $17.3,19.2$ and $22.3^{\circ} \mathrm{ShD}$ for samples PUMIX_0.9, PUMIX_0.95 and PUMIX_1.0, respectively.

\section{Melt flow index}

Melt flow index (MFI) is a parameter that plays a significant role in the thermoplastic industry for assessing the processability of obtained materials [20] and the determination of the uncertainty associated with the measurements. To evaluate the influence of test parameters on the measurement of MFI the design of experiments (DOE). There are two methods for MFI results presentation, as mass and volume melt flow rates (Melt Mass-Flow Rate, $M F R$ and Melt Volume-Flow Rate, $M V R$, respectively). The values of MFR and MVR obtained for synthesized poly(ether-urethane)s are demonstrated in Table 6. 
T a b 1 e 6. Melt mass-flow rate (MFR) and melt volume-flow rate (MVR) of synthesized poly(ether-urethane)s

\begin{tabular}{c|c|c}
\hline Code of sample & MFR g/10 min & $\begin{array}{c}M V R \\
\mathrm{~cm}^{3} / 10 \mathrm{~min}\end{array}$ \\
\hline PU1000_0.9 & $40.2 \pm 2.3$ & $39.8 \pm 2.5$ \\
PU1000_0.95 & $30.5 \pm 1.5$ & $30.1 \pm 1.1$ \\
PU1000_1.0 & $6.3 \pm 0.8$ & $6.1 \pm 0.1$ \\
PU2700_0.9 & $24.2 \pm 1.1$ & $23.8 \pm 0.9$ \\
PU2700_0.95 & $7.82 \pm 1.3$ & $7.65 \pm 0.3$ \\
PU2700_1.0 & $2.2 \pm 0.2$ & $2.1 \pm 0.2$ \\
PUMIX_0.9 & $32.2 \pm 1.1$ & $31.6 \pm 0.8$ \\
PUMIX_0.95 & $15.3 \pm 1.4$ & $14.7 \pm 1.1$ \\
PUMIX_1.0 & $3.8 \pm 0.4$ & $2.5 \pm 0.6$ \\
\hline
\end{tabular}

The MFR and MVR were experimentally determined at a temperature of $175^{\circ} \mathrm{C}$. It is seen that the values decreased with increasing $[\mathrm{NCO}] /[\mathrm{OH}]$ molar ratio during the prepolymer chain extending step. This is closely connected to the content of hard segments in the prepared polyurethanes. As mentioned earlier, the concentration of hard segments decreased with an increase in $[\mathrm{NCO}] /[\mathrm{OH}]$ molar ratio of the prepolymer. This dependence is related to the fraction of hydrogen-bonded carbonyl groups. Lower values of melt flow index are obtained when the concentration of hydrogen bonds is higher [4]. Breaking a large number of hydrogen bonds requires increased temperature or pressure. The highest values of MFR and MVR were obtained for PU1000 series, slightly lower for the PUMIX series and the lowest for PU2700 samples. This finding is following the assumption that results are associated with hard segments concentration in the chemical structure of obtained materials. In all cases, the values also decrease as the $[\mathrm{NCO} / \mathrm{OH}]$ molar ratio increases.

\section{CONCLUSION}

The obtained results allowed to confirm that the mixture of the prepolymers based on two different polyether polyols led to thermoplastic poly(ether-urethane)s characterized by good thermal, thermo-mechanical and mechanical properties. Prepared materials revealed a high degree of phase separation which have a great influence on the resulted properties. Thermal analysis verified the thermal stability of the obtained bio-TPURs at the temperature $c a \cdot 315^{\circ} \mathrm{C}$. Moreover, the mechanical tests confirmed that the use of prepolymers mixture did not affect significantly the tensile strength of the materials. Nevertheless, the molar ratio of the $[\mathrm{NCO}] /[\mathrm{OH}]$ groups has a huge influence on the tensile properties. With increasing $[\mathrm{NCO}] /[\mathrm{OH}]$ groups molar ratio, the tensile strength, elongation at break and hardness also increase. It was confirmed, that this trend is related to the segmented structure of the TPURs. With increasing $[\mathrm{NCO}] /[\mathrm{OH}]$ groups molar ratio, the degree of phase separation decrease. Furthermore, MFI decreases as the $[\mathrm{NCO}] /[\mathrm{OH}]$ groups molar ratio increases, suggesting poorer processability and requiring higher energy inputs to reprocess the material. This is due to the higher molecular weight of the polymer. The best performance of the elastomeric products was obtained when the molar ratio of the $[\mathrm{NCO}] /[\mathrm{OH}]$ groups equal to 0.95 . This molar ratio permits to obtain materials with good properties, both mechanical and processing. The use of the mixture of the prepolymers allows the better modification and control of the physicochemical properties. Synthesized materials are characterized by better mechanical properties and most importantly melt flow index in comparison to polyurethanes obtained using one prepolymer with the molecular mass in the range from 1900 to $2100 \mathrm{~g} / \mathrm{mol}$.

\section{ACKNOWLEDGMENT}

The authors wish to thank BASF (Germany) and Allessa (Germany) for kindly providing bio-based 1.4-butanediol and bio-based poly(trimethylene polyol).

\section{REFERENCES}

[1] Prociak A., Rokicki G., Ryszkowska J.: „Materiały poliuretanowe", Wydawnictwo Naukowe PWN, Warszawa 2014.

[2] Ionescu M.: "Chemistry and Technology of Polyols for Polyurethane", First Edit, Rapra Technology Limited, United Kingdom 2005. http://dx.doi.org/10.1002/pi.2159

[3] Wirpsza Z.: „Poliuretany. Chemia, technologia, zastosowanie", Wydawnictwo Naukowo-Techniczne, Warszawa 1991.

[4] Kasprzyk P., Datta J.: Polymer 2019, 160, 1. http://dx.doi.org/10.1016/j.polymer.2018.11.032

[5] Shen Z., Zheng L., Li C. et al.: Polymer 2019, 175, 186. http://dx.doi.org/10.1016/j.polymer.2019.05.010

[6] Kumagai S., Motokucho S., Yabuki R. et al.: Journal of Analytical and Applied Pyrolysis 2017, 126, 337. http://dx.doi.org/10.1016/j.jaap.2017.05.012

[7] Sáenz-Pérez M., Lizundia E., Laza J.M. et al.: RSC Advances 2016, 6, 69094. http://dx.doi.org/10.1039/c6ra13492k

[8] Parcheta P., Głowińska E., Datta J.: European Polymer Journal 2020, 123, 1. http://dx.doi.org/10.1016/j.eurpolymj.2019.109422

[9] Kasprzyk P., Sadowska E., Datta J.: Journal of Polymers and the Environment 2019, 27, 2588. http://dx.doi.org/10.1007/s10924-019-01543-7

[10] Datta J., Kasprzyk P., Błażek K., Włoch M.: Journal of Thermal Analysis and Calorimetry 2017, 130, 261. http://dx.doi.org/10.1007/s10973-017-6558-z

[11] Eceiza A., Martin M.D., de la Caba K. et al.: Polymer Engineering and Science 2008, 48, 297. http://dx.doi.org/10.1002/pen.20905

[12] Bistričić L., Baranović G., Leskovac M., Bajsić E.G.: European Polymer Journal 2010, 46, 1975. http://dx.doi.org/10.1016/j.eurpolymj.2010.08.001 
[13] Klinedinst D.B., Yilgör I., Yilgör E. et al.: Polymer 2012, $53,5358$. http://dx.doi.org/10.1016/j.polymer.2012.08.005

[14] Corcuera M.A., Rueda L., Saralegui A. et al.: Journal of Applied Polymer Science 2011, 122, 3677. http://dx.doi.org/10.1002/app.34781

[15] Głowińska E., Datta J., Parcheta P.: Journal of Thermal Analysis and Calorimetry 2017, 130, 113. http://dx.doi.org/10.1007/s10973-017-6293-5

[16] Głowińska E., Datta J.: Cellulose 2015, 22, 2471. http://dx.doi.org/10.1007/s10570-015-0685-0

[17] Kasprzyk P., Datta J.: Polymer Engineering and Science 2018, 58, E199. http://dx.doi.org/10.1002/pen.24874

[18] Calvo-Correas T., Santamaria-Echart A., Saralegi A. et al.: European Polymer Journal 2015, 70, 173. http://dx.doi.org/10.1016/j.eurpolymj.2015.07.022

[19] Saralegi A., Rueda L., Fernández-D’Arlas B. et al.: Polymer International 2013, 62, 106. http://dx.doi.org/10.1002/pi.4330

[20] Guerreiro S.D.C., João I.M., Real L.E.P.: Polymer Testing 2012, 31, 1026.

http://dx.doi.org/10.1016/j.polymertesting.2012.07.008 Received 28.IV 2020. 